\title{
Scanning Micrographs of the Ameloblasts and Enamel Rods of Rat Incisors
}

\author{
by \\ Masahiko AJISAKA,* Masahiro YOSHIDA,* Takahiro SAITO,* \\ Kazunori MORIMOTO,* Keishi SUMIMOTO* and Yoshihisa TODA*
}

Incisors of the rodent family are widely used as a convenient material for the study of odontogenesis, and the rodent otontogenic cells have been electron microscopically and histologically studied in recent years.

With the introduction of a scanning electron microscope, various dental tissues have been investigated by this useful research tool. Even so, the published literature on the odontogenic cells in the light of scanning microscopy is still scanty. BoyDE[1] reported his findings on scanning micrographs of the canine ameloblasts and IsOKAWA et al.[2] on the odontoblasts of man respectively. Since the work of BoyDE was not chiefly directed to the observation of aemloblasts, he did not describe details of the ameloblastic cells themselves.

The present study is concerned with a scanning micrographic inquiry of the ameloblasts of rat incisors together with the enamel rods.

\section{Material and Methods}

For the study purposes, use was made of adult rats which were sacrificed by beheading their heads. Immediately after the beheading, the incisors were surgically removed from the jaw together with a slight surrounding tissues and were fixed in a $1 \%$ solution of buffered osmic acid for 3 hours. After fixation, it was dehydrated and dried in a conventional method. After thoroughly dried, the developing root end of incisors was carefully fractured and the portion which exposed the ameloblastic cells. For observations with a scanning electron microscope (JSM type II, Japan Electron Optic Co. Ltd., Tokyo), the specimen was coated with gold on the surface.

\section{Observations}

The high columnar ameloblasts are found in the state of a layer of cells and are linked to the enamel rods by way of what appeares to be membraneous (Fig. 1). These enamel rods are arranged in a parallel to one another near the ameloblasts, i.e.,

\footnotetext{
* 鯵坂正彦, 吉田昌弘, 斉藤高弘, 森本一徳, 炭本圭之, 戸田善久, Department of Anatomy, Nihon University School of Dentistry, Tokyo (Director: Prof. Sohiti ISOKAWA).
} 


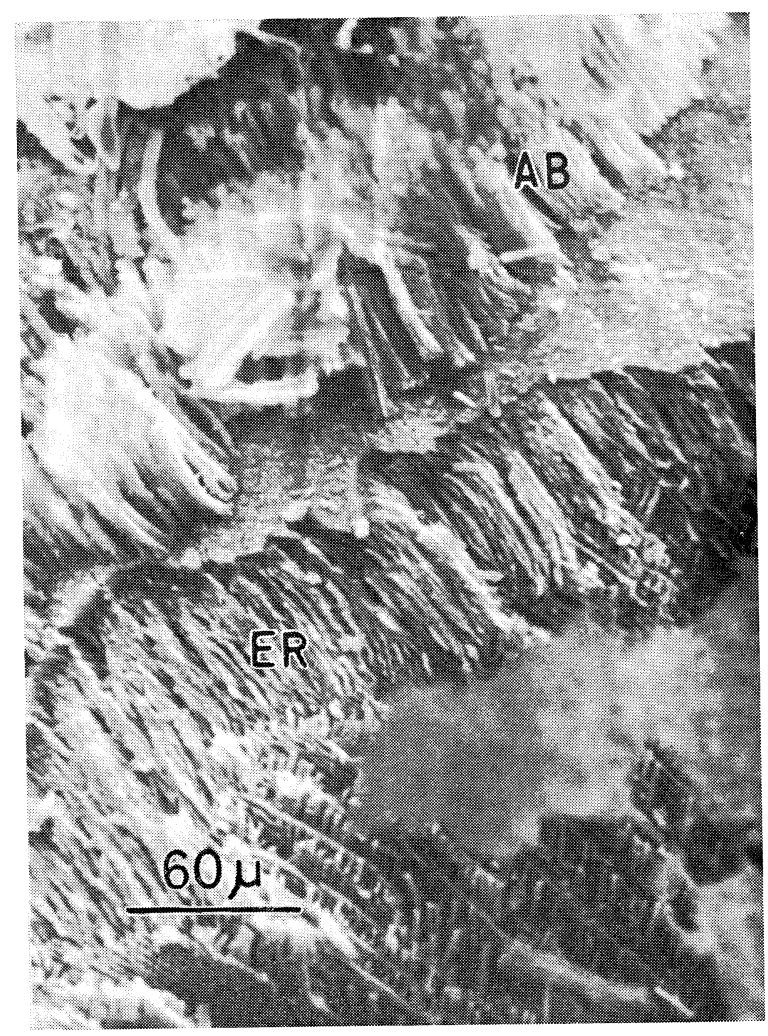

Fig. 1

Low magnification of an ameloblastic layer $(\mathrm{AB})$ and enamel rods (ER) of the surface enamel area in the rat incisor tooth

surface enamel area but, in the deep lying enamel area, the rods are decussate characteristic of the rodent enamel.

The enamel rods in surface enamel area are seen to be ranged as if plates, which are made up of accumulations of fibrous substances (Figs. 2, 4).

In the deep lying enamel area, on the other hand, somewhat thicker rods cross one another or decussate (Figs. 2, 3). Occasionally there are seen images where these columnar rods are fused one another by some sort of cementing substance (Fig. 3).

But, according to Fig. 5, what appears to be a cementing substance is nothing but a fibrous filament and the latter filamtnt is of the same substance that constitutes the enamel rods. That accumulations of this fibrous filament make up the enamel rods, is easily demonstrated by Figs. 4 and 6. An ameloblast is measured to be about $40 \mu$ in height and its basal end is connected to what appears to be membraneous under a low magnification. From the height, this ameloblast is assumed to be one which recently completed its amelogenesis. On the other hand, an end of a layer of parallelrunning rods on the other side of what appears to be a membrane comes to an abrupt stop (Fig. 7).

Our natural assumption was that there would be terminal bars and Tomes' processes in this membraneous area as a developing front of enamel but detailed observations of this area were not possible. 
Fig. 2

Two different arrangements of enamel rods. Top is a surface enamel area, bottom is a deep lying enamel area.
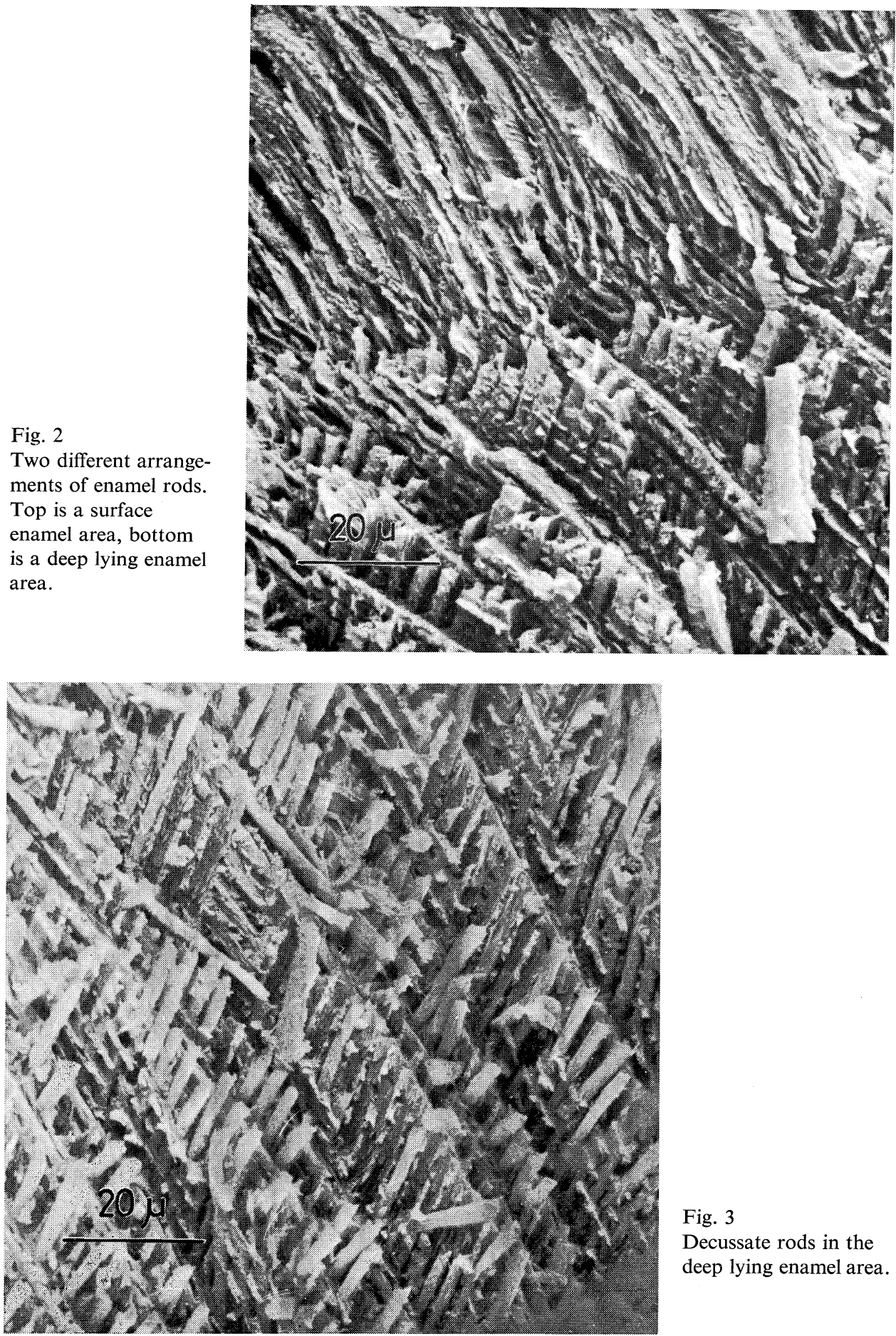

Fig. 3

Decussate rods in the deep lying enamel area. 

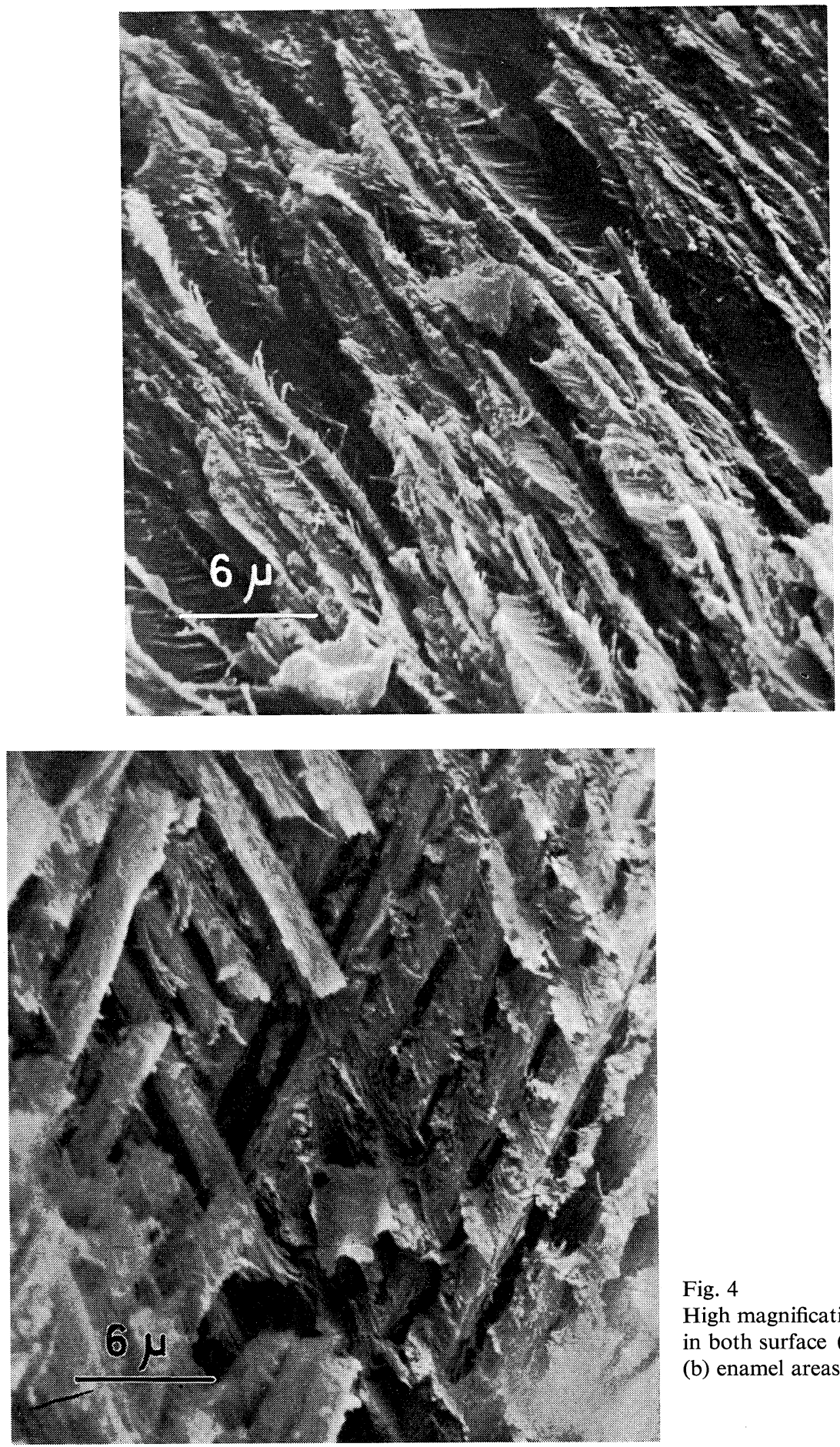

Fig. 4

High magnification of rods

in both surface (A) and deep

(b) enamel areas. 


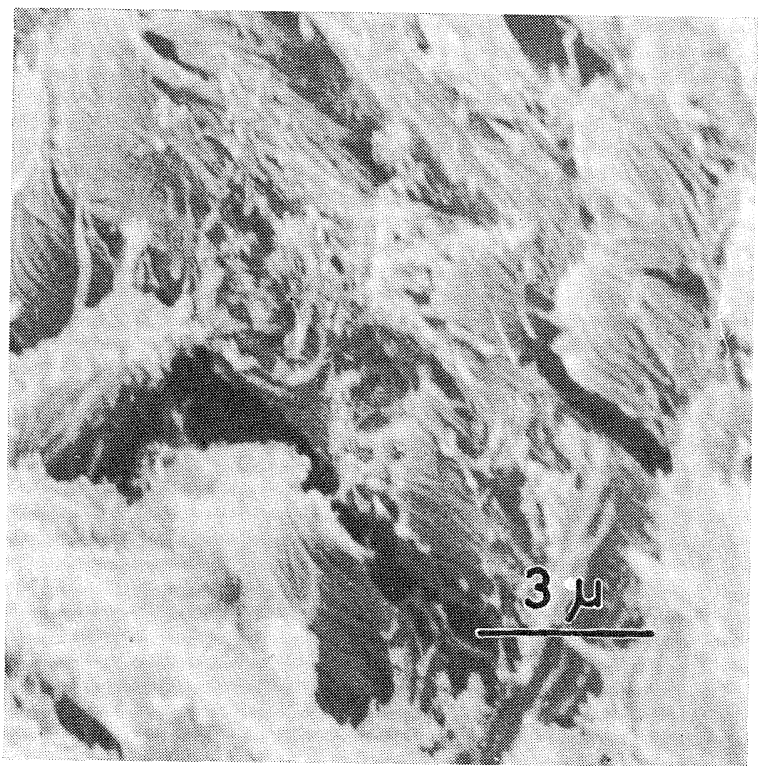

Fig. 5 Higher magnification of rat enamel rods. They are made up of the accumulations of the fibrous filaments.

Fig. 6

Ameloblastic layer, membraneous structure and enamel rods of surface enamel area.

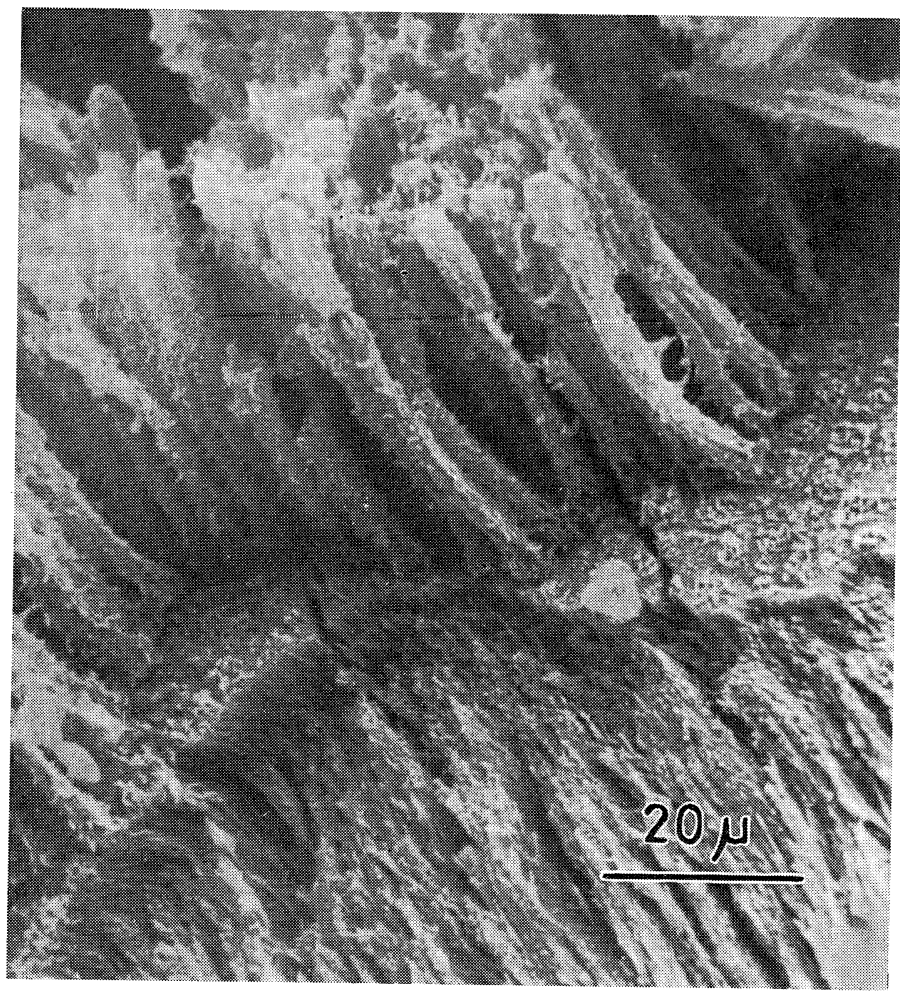




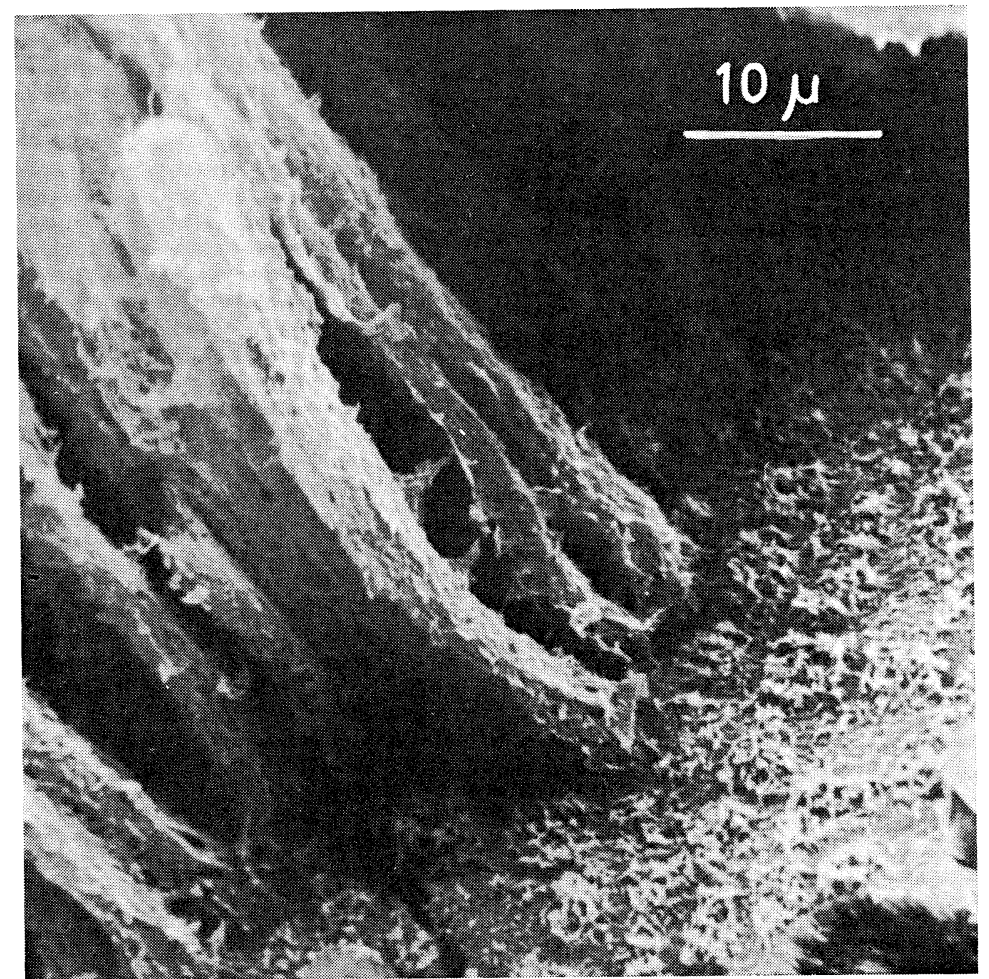

Fig. 7 Ameloblasts and the hexagons showing the remains of cells had existed.

Under a magnified view of the ameloblast (Fig. 8), minute structures as a cell are not observable because of treatment for a specimen. The ameloblast is connected with adjacent cells and thus linked to the developing front of enamel, however, part of the ameloblast is removed. In that spot, evidence is observable from the remains of regularly arranged hexagono that ameloblasts had previously existed. It may be that they were terminal bars.

\section{Discussion and Conclusion}

It is not always easy even with a scanning electron microscope to observe details of a single cell and imperfectly calcified enamel immediately after its formation with a high accuracy. Reasons for this are that a material has to be subjected to the fixation, dehydration and drying so as to prepare it as a specimen for subsequent observations.

In the present study, the authors successfully obtained scanning micrographs of the enamel rod arrangement characteristic of a rodent. Although the enamel rods are observed to be made up of the accumulation of fibrous filaments, it will have to be yet determined as to the relationship between these fibrous filaments and inorganic crystals constituting the enamel rods.

It was demonstrated by ICHIJO[3] that crystals of one enamel rod are not con- 
nected with those of another rod. The same is true of the fibrous filaments according to our observations.

Although we could not observe the terminal bars and Tomes' processes in detail, we fully observed the remains of regularly arranged hexagons in what appeared to be a membraneous region, to which ameloblasts must have been previously attached. It will be of much interest to compare these ameloblastic remains with the crosssections of rodent enamel rods demonstrated by SHOBUSAWA.

The height of an ameloblast is said to reach nearly $60-70 \mu$ by the formation of enamel matrix[3] and our observation of the height in the neighborhood of $40 \mu$ confirmed the view that the ameloblasts under observation recently passed the stage of matrix formation. For this reason, a layer of parallel rods seen beneath the ameloblasts was a surface enamel layer in the future.

\section{References}

[1] Boyde, A.: The development of enamel structure; Proc. Roy. Soc. Med., Vol. 60, 923-928, (1967).

[2] Isokawa, S., Toda, Y., Kodama, N. and Inoue, Y: Scanning electron microscope of human odontoblasts and predentin; J. Nihon Univ. Sch. Dent., Vol. 12, 54-56, (1970).

[3] ICHIJo, T.: Morphological and structural changes and the enamel matrix formation of ameloblast in the developmental stage; Symposium of dental hard tissue formation, II., 306-342, Ishiyaku Shuppan Co. Ltd., Tokyo, (1969).

[4] Shobusawa, M.: Vergleichende Untersuchungen über die Form der Schmelzprismen der Säugetiere; Okajima's Folia Anat. Japon., Bd. 24, 371-392, (1952). 